\title{
Abnormal retinal vascular development in IL-18 knockout mice
}

\author{
Hong Qiao $^{1}$, Koh-Hei Sonoda ${ }^{1}$, Yukio Sassa ${ }^{1}$, Toshio Hisatomi ${ }^{1}$, Hiroshi Yoshikawa ${ }^{1}$, \\ Yasuhiro Ikeda ${ }^{1}$, Toshinori Murata ${ }^{1}$, Shizuo Akira ${ }^{2}$ and Tatsuro Ishibashi ${ }^{1}$ \\ ${ }^{1}$ Department of Ophthalmology, Graduate School of Medical Sciences, Kyushu University, Fukuoka, Japan \\ and ${ }^{2}$ Department of Host Defense, Research Institute for Microbial Diseases, Osaka University, Osaka, Japan
}

\begin{abstract}
Recent studies have indicated that interleukin 18 (IL-18) might act as either an angiogenic or an angiostatic factor, but the true function of this protein in vascular development is unclear. We therefore investigated the role of IL-18 in the formation of retinal vessels. Development of the retinal vasculature was compared in IL-18 knockout (KO) and wild-type (WT) mice at several different time points. The formation of vessels was evaluated using angiography of flat-mounted retinal samples after inoculation with fluorescein dextran. Retinal samples from both groups were also evaluated through histological examinations, and the expression of angiogenic factors was examined using the reverse-transcription-polymerase chain reaction. The capillary retinal vessels in both WT and IL-18 KO mice had reached the peripheral retina by postnatal day (P) 7. However, IL-18 KO mice showed angiectasis and vascular leakage at P7, especially in the mid-peripheral retina. These symptoms were not observed in WT mice at any stage. Histopathological analysis confirmed abnormal vascular formation in IL-18 KO mice at P14. Interestingly, these abnormalities regressed over time and had disappeared by P84. Several angiogenesis-associated factors, including vascular endothelial growth factor (VEGF), basic fibroblastgrowth factor (bFGF), platelet-derived growth factor (PDGF) and pigment epithelium-derived factor (PEDF), were overexpressed in the retinas of IL-18 KO mice compared with those of WT mice at P14. Interferon- $\gamma$ was detected only in WT mouse retinas at P14. These results provide new evidence for the role of IL-18 in retinal vascular development.
\end{abstract}

Laboratory Investigation (2004) 84, 973-980, advance online publication, 3 May 2004; doi:10.1038/labinvest.3700115

Keywords: angiogenesis-associated factors; IL-18 knockout (IL-18 KO) mice; interleukin 18 (IL-18); retinal vascular development; abnormal vasculature

Interleukin 18 (IL-18), formerly called interferon- $\gamma$ (IFN- $\gamma$ )-inducing factor, is a pleiotropic proinflammatory cytokine that is produced by activated monocytes, glial cells and dendritic cells., ${ }^{1,2}$ This protein has immunoregulatory activities, including the induction of IFN- $\gamma$ production, ${ }^{3-5}$ the enhancement of natural killer cell activity and the proliferation of activated T cells. ${ }^{6-8}$ In addition, Cao et $a l^{9}$ reported that IL-18 suppressed basic fibroblastgrowth factor (bFGF)-induced corneal neovascularization and tumor angiogenesis. These findings indicate that IL-18 acts as an angiogenesis and tumor suppressor. ${ }^{9}$ By contrast, IL-18 has been shown to stimulate vascular endothelial growth factor (VEGF) induction and to promote endothelial cell migration. ${ }^{10,11}$ Moreover, IL-18 has also been

Correspondence: K-H Sonoda, MD, PhD, Department of Ophthalmology, Graduate School of Medical Sciences, Kyushu University, 3-1-1 Maidashi, Higashi-Ku, Fukuoka 812-8582, Japan.

E-mail: sonodak@med.kyushu-u.ac.jp

Received 3 September 2003; revised 20 March 2004; accepted 23 March 2004; published online 3 May 2004 reported to increase tube formation both in vitro and in vivo. ${ }^{11}$ The reason for the discrepancy among these results, and the true function of this protein, remain unclear. However, whether IL-18 acts as an angiogenic or an angiostatic factor, this molecule is a novel candidate for a role in vascular development and warrants further investigation.

The retinal vasculature is a good model system to study the general development of blood vessels. Although vascular development in the early embryo is difficult to observe, ${ }^{12}$ the murine retinal vascular system develops after birth ${ }^{13}$ and is therefore easier to examine. Expression of the $I L-18$ gene has been detected in both the iris and retina; ${ }^{14}$ however, the functions of IL-18 in the eyes remain largely unknown.

In this study, we investigated the retinal vascular system as a model for identifying the effects of IL-18 on vascular development using $I L-18$ knockout (KO) mice. Both angiogenic and angiostatic factors are thought to have a crucial role during the formation of blood vessels. ${ }^{15}$ We, therefore, also measured a panel of potential angiogenesis-associated factors in 
the retina using reverse-transcription-polymerase chain reaction (RT-PCR), including VEGF, plateletderived growth factor (PDGF), bFGF, pigment epithelium-derived factor (PEDF) and IFN- $\gamma$.

\section{Materials and methods}

\section{Experimental Animals}

Wild-type (WT) C57BL/6 mice were obtained from SLC Japan (Shizuoka, Japan). C57BL/6 IL-18 KO mice were generated in Hyogo College of Medicine, Japan. ${ }^{16}$ All of the animals were treated humanely and were housed under controlled pathogen-free conditions at Kyushu University, Japan.

\section{Fluorescein-Dextran Angiography of the Retinal Blood Vessels}

Flat-mounted retinas were evaluated using fluorescein-dextran angiography according to the protocol summarized below. ${ }^{17}$ The mice were deeply anesthetized and a $0.03 \mathrm{ml} / \mathrm{g}$ body weight $50 \mathrm{mg} / \mathrm{ml}$ solution of $2 \times 10^{6}$ molecular weight fluoresceindextran (Sigma, St Louis, MO, USA) was perfused through the left ventricle. The eyes were enucleated and fixed in $4 \%$ paraformaldehyde for at least $3 \mathrm{~h}$. The corneas and lenses were then removed, and the peripheral retinas were dissected and flat-mounted on microscope slides for examination under a fluorescence microscope. In order to objectively quantify the degree of retinal vascular abnormalities, the retinal scoring system described previously by Higgins et $a l^{17}$ was used, with some minor modifications (Table 1). Retinal angiography scores were given for the following categories: blood-vessel growth, blood-vessel leakage, abnormal vessels, nonperfusion area, retinal hemorrhages and tortuosity of the blood vessels. After scoring in a masked fashion, the scores for each category were summed and then matched with the corresponding degrees of severity in individual animals.

\section{Histological Analysis}

For the histological analysis, the eyes were enucleated, fixed in $4 \%$ paraformaldehyde and embedded in paraffin. Sections $(6 \mu \mathrm{m})$ were then prepared and stained with hematoxylin and eosin (HE) solution.

\section{Semiquantitative RT-PCR}

For the semiquantitative RT-PCR, mice $(n=3)$ were deeply anesthetized and the eyes were enucleated as described above. The corneas and lenses were removed, and the peripheral retinas were dissected. To examine gene expression in the retinas, total RNA samples were isolated using Trizol $^{\circledR}$ (Life Technologies, Gland Island, NY, USA) and were subjected to RT-PCR analysis using the protocol described previously by Sassa et al. ${ }^{18}$ Briefly, firststrand complementary DNA (cDNA) was synthesized using AMV reverse transcriptase (Boehringer Mannheim, Indianapolis, IN, USA) according to the manufacturer's guidelines. Incubation was carried out for $10 \mathrm{~min}$ at $25^{\circ} \mathrm{C}$ and $60 \mathrm{~min}$ at $42^{\circ} \mathrm{C}$. Reverse transcriptase (Boehringer Mannheim, Indianapolis, IN, USA) was denatured at $99^{\circ} \mathrm{C}$ for 5 min before PCR amplification. cDNA was then subjected to PCR in a $20 \mu \mathrm{l}$ volume containing $10 \mathrm{pmol}$ of the genespecific primer pair and $2 \mu \mathrm{l}$ of Light Cycler (Roche, Indianapolis, IN, USA). The PCR products were electrophoresed onto $2 \%$ agarose gels and stained with $0.05 \%$ ethidium bromide. The intensity of the ethidium bromide was measured using an image sensor (Densitograph, ATTO, TOKYO, Japan) with a computer-controlled display. The primers used are listed in Table 2.

Table 1 Retinal-vessel scoring system

\begin{tabular}{|c|c|c|c|c|c|}
\hline & \multicolumn{5}{|c|}{ Retinal-vessel score } \\
\hline & 0 & 1 & 2 & 3 & 4 \\
\hline $\begin{array}{l}\text { Blood vessel } \\
\text { growth }\end{array}$ & Complete & $\begin{array}{l}\text { Incomplete } \\
\text { outer third }\end{array}$ & $\begin{array}{l}\text { Incomplete } \\
\text { middle third }\end{array}$ & $\begin{array}{l}\text { Incomplete } \\
\text { inner third }\end{array}$ & \\
\hline $\begin{array}{l}\text { Blood vessel } \\
\text { leakage }\end{array}$ & None & $\begin{array}{l}\text { Few, scattered } \\
<3 \text { clock hours }\end{array}$ & 3-5 clock hours & 6-8 clock hours & $\begin{array}{l}9-12 \\
\text { clock } \\
\text { hours }\end{array}$ \\
\hline Abnormal vessels & None & $\begin{array}{l}\text { Mild }<3 \text { clock } \\
\text { hours }\end{array}$ & $\begin{array}{l}\text { Moderate 3-6 } \\
\text { clock hours }\end{array}$ & $\begin{array}{l}\text { Severe }>6 \text { clock } \\
\text { hours }\end{array}$ & \\
\hline Nonperfusion area & None & $\begin{array}{l}\text { Mild early zone } \\
1 \text { (inner } 50 \% \text { of } \\
\text { zone 1) }\end{array}$ & $\begin{array}{l}\text { Moderate } \\
\text { throughout zone } \\
1 \text { (outer of } 50 \% \\
\text { of zone 1) }\end{array}$ & $\begin{array}{l}\text { Severe } \\
\text { extending to } \\
\text { zone } 2\end{array}$ & \\
\hline Retinal hemorrhage & Absent & Present & & & \\
\hline $\begin{array}{l}\text { Blood vessel } \\
\text { tortuosity }\end{array}$ & None & Mild $<3$ clock & $\begin{array}{l}\text { Moderate 3-6 } \\
\text { clock }\end{array}$ & Severe $>6$ clock & \\
\hline
\end{tabular}


Table 2 Gene-specific primers for RT-PCR

\begin{tabular}{llc}
\hline Gene & Primer sequence $\left(5^{\prime}-3^{\prime}\right)$ & Product size (bp) \\
\hline VEGF & Sense GCGGGCTGCCTCGCAGT & $716\left(\mathrm{VEGF}^{188}\right), 644\left(\mathrm{VEGF}^{164}\right)$, \\
& Antisense TCACCGCCTTGGCTTGTCA & $512\left(\mathrm{VEGF}^{120}\right)$ \\
PDGF & Sense AGCATCCGGGACCTCCAG & 578 \\
$\mathrm{bFGF}$ & Antisense AAGACCGCACGCACATTGG & 380 \\
& Sense ACACGTCAAACTACAACTCCA & \\
$\mathrm{IFN}-\gamma$ & Antisense TCAGCTCTTAGCAGACATTGG & 213 \\
PEDF & Sense AGCGGCTGACTGAACTCAGATTGTAG & 507 \\
$\beta$-Actin & Antisense GTCACAGTTTTCAGCTGTATAGGG & 500 \\
& Sense AACGTCCTGCTGTCTCCACT & 500 \\
\hline
\end{tabular}
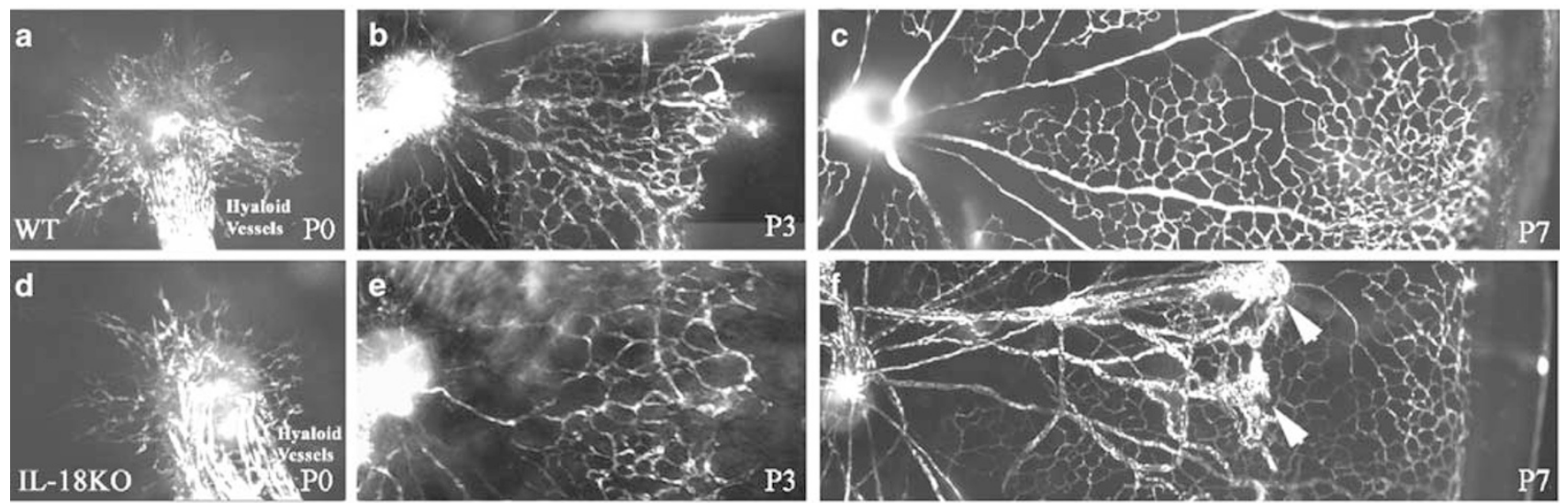

Figure 1 Retinal development visualized by fluorescein angiography in newborn mice. (a-c) Flat-mounted retinal samples of wild-type (WT) mice at postnatal day (P) 0 , P3 and P7, respectively (original magnification $\times 100$ ). (d-f) Flat-mounted retinal samples of $I L-18$ knockout $(\mathrm{KO})$ mice at P0, P3 and P7, respectively (original magnification $\times 100$ ). At P0, vascular sprouts are visible around the optic nerve in both WT and $I L-18 \mathrm{KO}$ mice (a, d). The primary vascular network has spread throughout approximately one-half of the retina by P3 and shows several capillary-free zones (b, e). IL-18 KO mice show angiectasis and vascular leakage at P7 (f, arrowhead).

\section{Statistical Analysis}

The data were expressed as the mean \pm standard deviation (s.d.). Differences among the experimental groups were analyzed using the Student's $t$-test. Probability $(P)$ values $\leq 0.05$ were considered to be statistically significant.

\section{Results}

IL-18 KO mice have previously been reported to develop normally, with no obvious signs of disease. ${ }^{16}$ However, significant differences in vascular development were detected between WT and $I L-18$ KO mice in this study using fluorescein-dextran retinal angiography. Retinal angiography was performed in both types of mouse at several intervals during the vascular development period (as described below) and at least 10 eyes were examined at each time interval.

\section{Abnormalities in Early Retinal Development}

To investigate the effect of IL-18 on early retinal angiogenesis, we compared the flat-mounted retinas of WT and $I L-18 \mathrm{KO}$ mice at postnatal day (P) 0, P3 and P7 (Figure 1). In the WT mice, ring-shaped vascular sprouts were observed around the optic nerve in newborn (P0) animals (Figure 1a). The primary capillary vessels had spread approximately halfway across the retina by P3 (Figure 1b) and had reached the periphery by 1 week after birth (P7; Figure 1c). IL-18 KO mice also showed vascular sprouts at P0 (Figure 1d, and primary retinal capillary development was similar to that of WT mice at P3 and P7 (Figure 1e and f). However, $I L-18$ $\mathrm{KO}$ mice showed angiectasis and vascular leakage, especially in the mid-peripheral retina, at P7 (Figure 1f). These symptoms were not observed in WT mice at any stage.

We further investigated the retinal abnormalities in $I L-18 \mathrm{KO}$ mice at P14. Retinal angiography of the 
control WT mice revealed an evenly distributed and well-differentiated capillary network (Figure 2a and b). By contrast, the retinas of the $I L-18 \mathrm{KO}$ mice showed the vascular leakage and several areas of nonperfusion (Figure 2c and d).

The HE-stained sections of the retinas of both WT $(n=10)$ and $I L-18 \mathrm{KO}(n=10)$ mice at P14 were microscopically examined (Figure 3). In the control WT mice, the retinal vessels were distributed throughout the nerve-fiber layer, ganglion-cell layer, inner plexiform layer, inner nuclear layer and outer plexiform layer. The retinal vascular capillaries were compact and well defined in both the inner nuclear layer and the outer plexiform layer (Figure $3 \mathrm{a}$ and b). However, abnormal retinal vessels were seen to have crossed the inner-limiting membrane in $I L-18 \mathrm{KO}$ mice (Figure 3c). In addition, the retinal capillaries in $I L-18 \mathrm{KO}$ mice were frequently dilated (Figure 2d), which might correspond to the vascular leakage observed by retinal angiography (Figure 2c and d). There was no evidence of inflammatory cell infiltration in $I L-18 \mathrm{KO}$ mice (Figure 3c and d).

\section{Disappearance of Retinal Vessel Abnormalities by P84}

To investigate the fate of the abnormal vessels observed in $I L-18 \mathrm{KO}$ mice, we followed up the condition of the retinal vessels at P35, P49 and P84. Interestingly, the vascular leakage and areas of nonperfusion had begun to decrease by P35 (Figure 4a) and had almost disappeared by P84 (Figure 4b).

The retinal scoring system summarized in Table 1 was used to objectively quantify the degree of retinal vascular abnormalities observed. At P14, the scores for the $I L-18 \mathrm{KO}$ mice were significantly higher than those for the WT mice. However, the abnormal
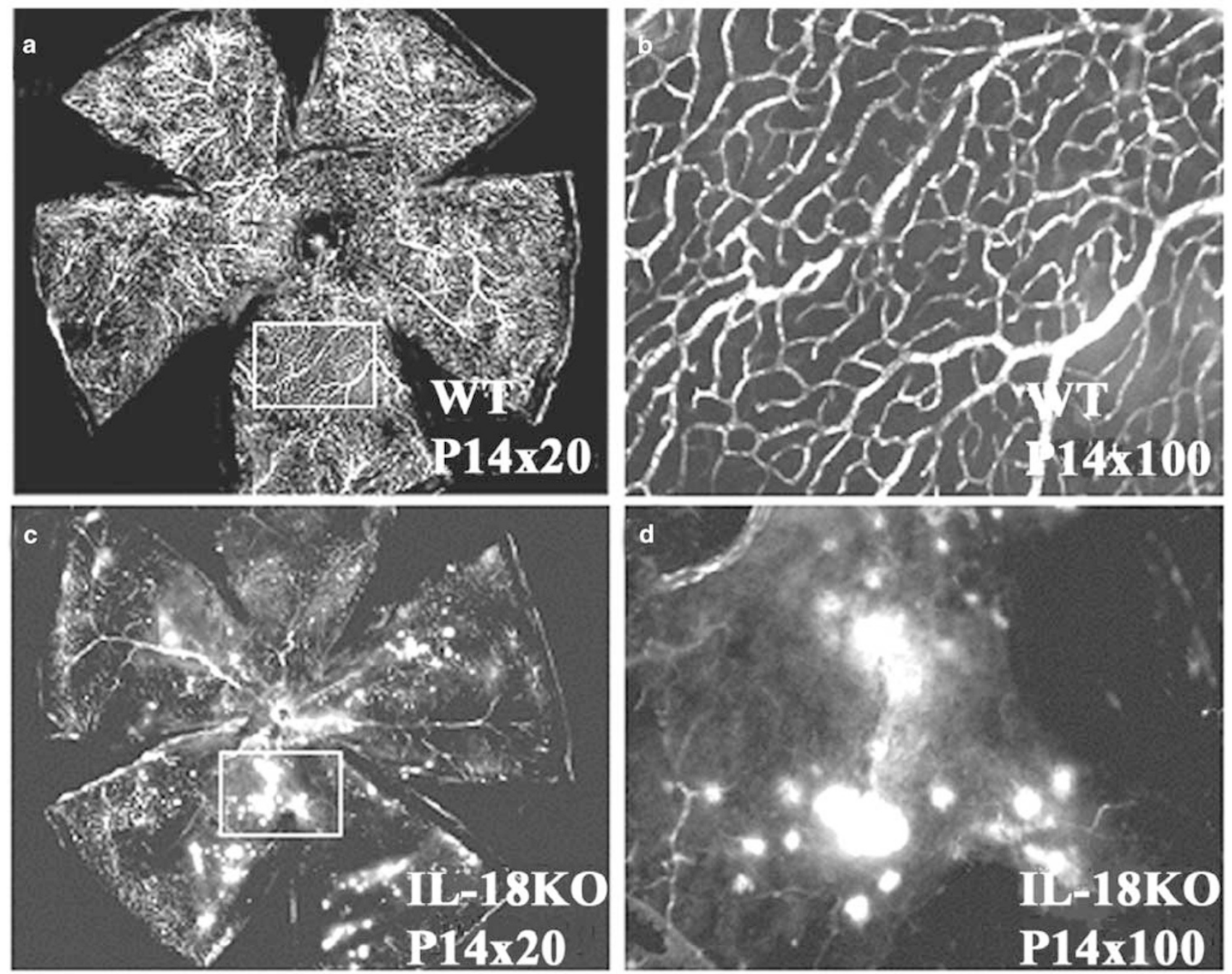

Figure 2 Fluorescein-dextran perfused flat-mounted remains at postnatal day 14. (a, b) Flat-mounted retinal samples of wild-type (WT) mice at postnatal day (P) 14, showing an evenly distributed stained capillary network (original magnifications $\times 20$ and $\times 100$, respectively). (c, d) Flat-mounted retinal samples of IL-18 KO mice at P14, showing the vascular leakage, areas of nonperfusion and blood-vessel tortuosity. Higher magnification of the vascular leakage and areas of nonperfusion are shown in part (d) (original magnifications $\times 20$ and $\times 100$, respectively). 

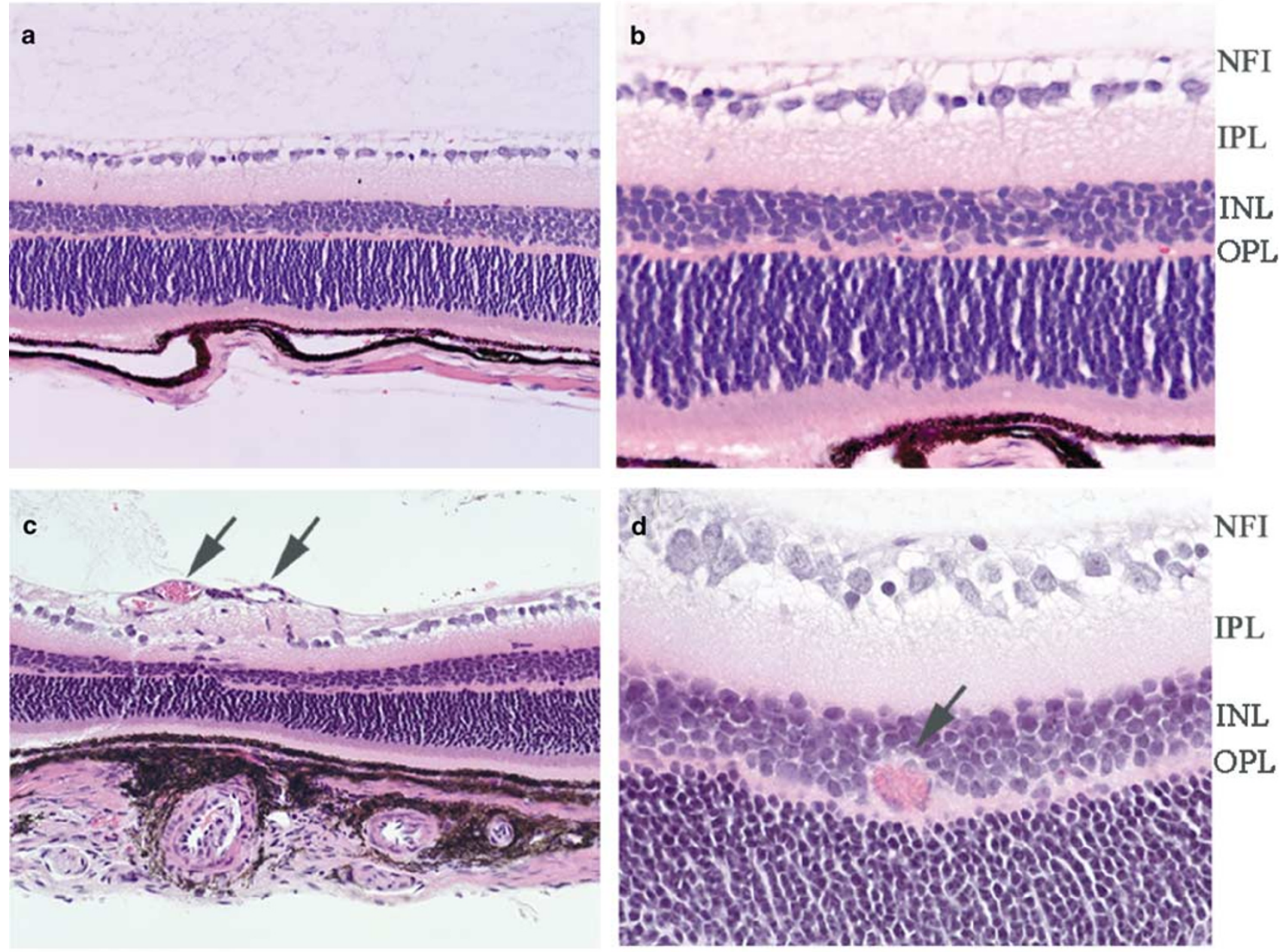

Figure 3 Histopathological analysis. (a, b) Representative hematoxylin and eosin (HE) stainings of retinal sections of WT mice at postnatal day $(\mathrm{P}) 14$ (original magnifications $\times 200$ and $\times 400$, respectively). (c, d) Representative HE stainings of retinal sections of $I L-18$ KO mice at P14 (original magnifications $\times 200$ and $\times 400$, respectively). Abnormal vessels are present in the vitreous space (arrowhead), which extend across the inner-limiting membrane (ILM) (c). A small vascular leakage (arrowhead) is present in the inner nuclear layer (INL) (d). A total of 12 eyes were examined for each group.

scores decreased over time and had reached normal levels by P84 (Figure 4c; $n=10$ for each group).

\section{Upregulation of Angiogenesis-Associated Factors}

Gene expression of angiogenesis-associated factors (VEGF, PDGF-A, bFGF, IFN- $\gamma$ and PEDF) in the developing mouse retinas was determined at P14 and P84 using RT-PCR (Figure 5). VEGF and bFGF were upregulated in the $I L-18 \mathrm{KO}$ mouse retinas compared to those of the WT mice at both P14 and P84. Although $P D G F-A$ expression was increased in the $I L-18 \mathrm{KO}$ mice at $\mathrm{P} 14$, this phenomenon was not observed at P84. IFN- $\gamma$ was only detected in the P14 WT mouse retinas. Interestingly, the antiangiogenic factor PEDF was only upregulated in $I L-18 \mathrm{KO}$ mouse retinas at P14.

\section{Discussion}

In this paper, we report for the first time that the retinas of $I L-18 \mathrm{KO}$ mice have abnormal vasculature and overexpress several angiogenesis-associated factors during early development. Interestingly, the abnormalities caused by IL-18 deficiency are no longer seen by P84.

Our data suggest that IL-18 has a specific role in the formation of retinal vessels. The baseline expression of endogenous IL-18 might regulate several potential angiogenic factors in the retina, as the absence of IL-18 leads to the abundant expression of several angiogenic factors. Previously, a study of the mechanisms of tumor rejection indicated that the inhibition of tumor angiogenesis, rather than antigen-specific immune responses, was most likely to account for the antitumor effects of IL$18 .^{19}$ Similar antiangiogenic effects were reported in another $I L-18$ KO mouse model. ${ }^{20}$ These results 

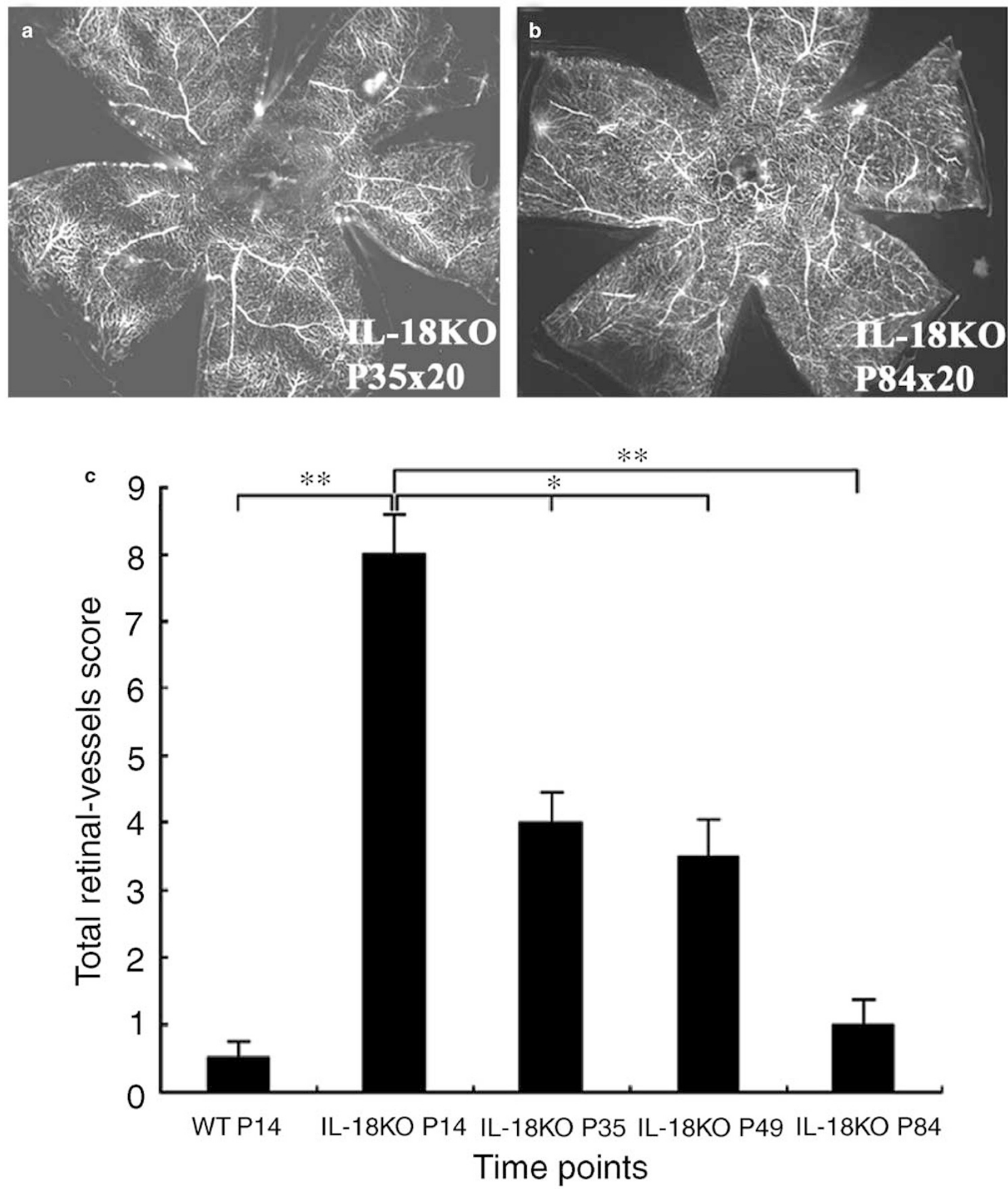

Figure 4 Fluorescein-dextran-perfused flat-mounted retinal samples after postnatal day 14. (a) Flat-mounted retinal samples of $I L-18$ KO mice at postnatal day (P) 35 (original magnification $\times 20$ ). (b) Flat-mounted retinal samples of IL-18 KO mice at P84 (original magnification $\times 20$ ). The vascular leakage and blood-vessel tortuosity has mostly regressed (original magnification $\times 20$ ). A minimum of 10 eyes were examined at each time interval. (c) The time course of changes in retinal angiography scores obtained using the retinal scoring system described in Table 1 . The results represent the mean score \pm the standard deviation (s.d.; $n=10$ for each group). ${ }^{*} P<0.05$; ${ }^{* *} P<0.01$. 

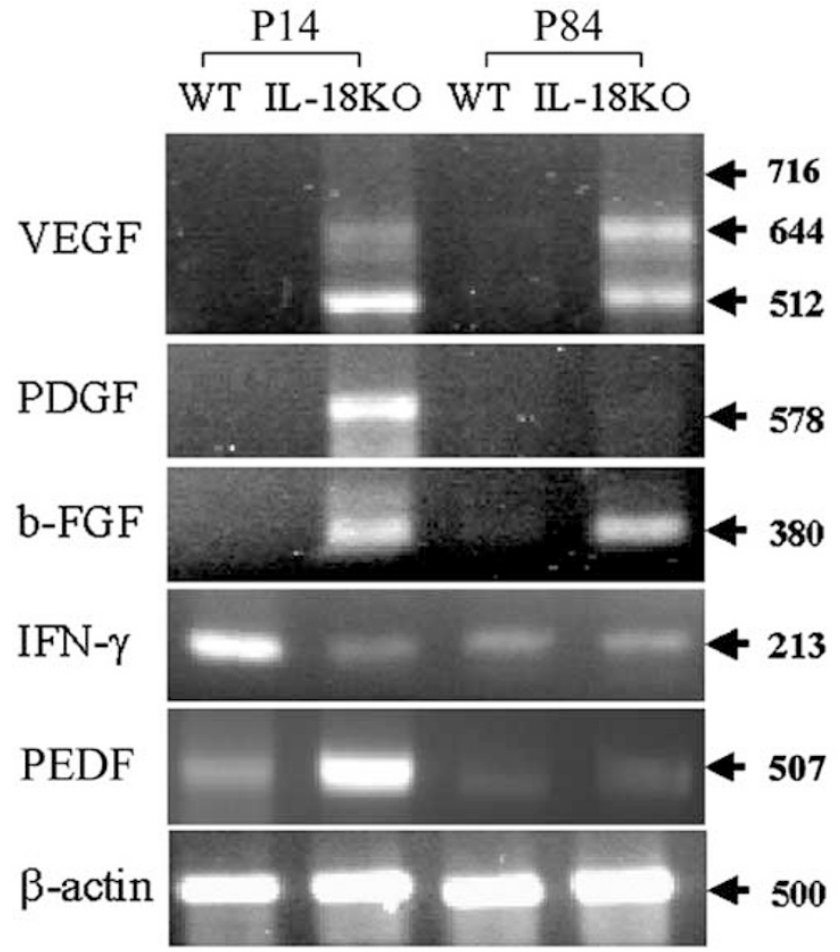

Figure 5 Analysis of the gene expression of angiogenic factors in the retina. Messenger RNA expression of angiogenesis-associated factors (vascular endothelial growth factor (VEGF), plateletderived growth factor-A (PDGF-A), basic fibroblast-growth factor (bFGF), interferon- $\gamma$ (IFN- $\gamma$ ), pigment epithelium-derived factor (PEDF) and $\beta$-actin) in developing mouse retinas as determined using RT-PCR. Lane 1: wild-type (WT) at postnatal day (P) 14. Lane 2; IL-18 knockout (KO) at P14. Lane 3; WT at P84. Lane 4; IL-18 KO at P84.

suggest that endogenous IL-18 might have an antiangiogenic role in the development of the retinal vasculature.

The local upregulation of $V E G F$ mRNA was previously reported in $I L-18 \mathrm{KO}$ mice after ischemic injury. ${ }^{20}$ The present study confirmed the overexpression of $V E G F$ in the retinas of $I L-18 \mathrm{KO}$ mice. Further examination of other angiogenesis-associated factors revealed that the $b F G F$ and $P D G F-A$ genes were also upregulated in the retinas of P14 IL$18 \mathrm{KO}$ mice. These data indicate that the upregulation of angiogenic factors might cause the abnormalities of the retinal vessels observed in $I L-18 \mathrm{KO}$ mice. However, the precise mechanisms that are responsible for the inhibitory effects of IL-18 on angiogenesis-associated factors in WT mice remain to be elucidated.

Expression of the $I F N-\gamma$ gene, which is promoted by IL-18, ${ }^{1,2}$ was only detected in P14 WT mouse retinas and had been significantly reduced by P84 (Figure 4). IFN- $\gamma$ has been reported to inhibit tumor angiogenesis; ${ }^{21-23}$ therefore, it might regulate the formation of retinal vessels. IFN- $\gamma$ mRNA was present at low levels in the $I L-18 \mathrm{KO}$ mice, even at P14. The decrease in angiostatic IFN- $\gamma$ might be another factor leading to abnormal retinal vascular formation in $I L-18 \mathrm{KO}$ mice. In fact, the fluorescein angiography revealed some areas of increased vascular permeability in newborn IFN- $\gamma \mathrm{KO}$ mice (data not shown). Unfortunately, the source of IFN- $\gamma$ and the mechanism of regulating other angiogenic factors are currently unknown. However, it has been reported that ocular-infiltrating $\mathrm{T}$ cells could produce IFN- $\gamma^{24,25}$ and IFN- $\gamma$ has been shown to have some antiangiogenic activity through a regulation of the angiogenic factors (eg VEGF, FGF). ${ }^{22,23}$

However, in contrast to the theory presented above, another possible mechanism might explain the retinal abnormalities in $I L-18 \mathrm{KO}$ mice: endogenous IL-18 might promote vascular network formation, as IL-18 is known to accelerate endothelial cell migration and tube formation in vitro. ${ }^{11}$ Our study revealed expanding areas of nonperfusion in IL-18 KO mouse retinas at P14 (Figure 2c and d). In the $I L-18 \mathrm{KO}$ mice, the immature vascular network easily formed avascular areas and several secondary angiogenic factors were produced, as is also observed in diabetic retinopathy and retinopathy of prematurity.

Notably, the anatomical abnormalities caused by IL-18 deficiency were no longer present at P84. The reasons for this recovery are unknown. However, we propose that antiangiogenic factors were produced during retinal vascular formation in the $I L-18 \mathrm{KO}$ mice to restore the physiological conditions. In fact, one of the antiangiogenic factors, PEDF, was upregulated in P14 IL-18 KO mice (Figure 5). Alternatively, Ishida et $a l^{26}$ recently demonstrated that retinal adherent leukocytes can induce apoptosis and might destroy abnormal vessels.

We need to discuss about the source of IL-18 during retinal development. The macrophages and polymorphonuclear cells are the candidate source of IL-18, but these cells were not observed in P14 retinas (Figure $3 \mathrm{~d}$ ). It is known that monocytelineage antigen-presenting cells, such as microglial cells, existed in the retina. Since microglial cells can produce IL-18 by various stimuli, ${ }^{27,28}$ we currently think resident microgila-derived IL-18 might affect the retinal vascular formation. The precise mechanism about the source of IL-18 needs to be elucidated in future studies.

In conclusion, we investigated the effects of IL-18 on murine retinal vascular formation and revealed that IL-18 regulates angiogenesis-associated factors, either directly or indirectly. Our findings also suggest that IL-18 might regulate early vascular development in general.

\section{Acknowledgements}

This work was supported in part by grants from the Ministry of Education, Science, Sports and Culture, Japan (B2 No. 14770962 to K-H Sonoda) and the Japan National Society for the Prevention of Blindness (to K-H Sonoda). 


\section{References}

1 Nakamura K, Okamura H, Wada M, et al. Endotoxininduced serum factor that stimulates gamma interferon production. Infect Immun 1989;57:590-595.

2 Dinarello CA. IL-18: a TH1-inducing, proinflammatory cytokine and new member of the IL-1 family. J Allergy Clin Immunol 1999;103:11-24.

3 Okamura H, Nagata K, Komatsu T, et al. A novel costimulatory factor for gamma interferon induction found in the livers of mice causes endotoxic shock. Infect Immun 1995;63:3966-3972.

4 Okamura H, Tsutsi H, Komatsu T, et al. Cloning of a new cytokine that induces IFN- $\gamma$ production by T cells. Nature 1995;378:88-91.

5 Kohno K, Kataoka J, Ohtsuki T, et al. IFN-gammainducing factor (IGIF) is a co-stimulatory factor on the activation of Th1 but not Th2 cells and exerts its effect independently of IL-12. J Immunol 1997;158: 1541-1550.

6 Matsui K, Yoshimoto T, Tsutsui H, et al. Propionibacterium acnes treatment diminishes CD4+NK1.1+T cells but induces type I T cells in the liver by induction of IL-12 and IL-18 production from Kupffer cells. J Immunol 1997;159:97-106.

7 Ushio S, Namba M, Okura T, et al. Cloning of the cDNA for human IFN-gamma-inducing factor, expression in Escherichia coli, and studies on the biologic activities of the protein. J Immunol 1996;156:4274-4279.

8 Okamura $\mathrm{H}$, Tsutsui $\mathrm{H}$, Kashiwamura S, et al. Interleukin-18: a novel cytokine that augments both innate and acquired immunity. Adv Immunol 1998;70:281-312.

9 Cao R, Farnebo J, Kurimoto M, Cao Y. Interleukin-18 acts as an angiogenesis and tumor suppressor. FASEB J 1999;13:2195-2202.

10 Matsumoto K, Kanmatsuse K. Interleukin-18 and interleukin-12 synergize to stimulate the production of vascular permeability factor by $\mathrm{T}$ lymphocytes in normal subjects and in patients with minimal-change nephrotic syndrome. Nephron 2000;85:127-133.

11 Park CC, Morel JC, Amin MA, et al. Evidence of IL-18 as a novel angiogenic mediator. J Immunol 2001;167: 1644-1653.

12 Fruttiger M. Development of the mouse retinal vasculature: angiogenesis versus vasculogenesis. Invest Ophthalmol Vis Sci 2002;43:522-527.

13 Stone J, Maslim J. Mechanisms of retinal angiogenesis. Prog Retinal Eye Res 1997;16:157-181.

14 Jiang HR, Wei X, Niedbala W, et al. IL-18 not required for IRBP peptide-induced EAU: studies in gene- deficient mice. Invest Ophthalmol Vis Sci 2001;42: 177-182.

15 Risau W. Mechanisms of angiogenesis. Nature 1997;386:671-674.

16 Takeda K, et al. Defective NK cell activity and Th1 response in IL-18-deficient mice. Immunity 1998;8: 383-390.

17 Higgins RD, Yu K, Sanders RJ, et al. Diltiazem reduces retinal neovascularization in a mouse model of oxygen induced retinopathy. Curr Eye Res 1999;18:20-27.

18 Sassa Y, Hata Y, Murata T, et al. Functional role of Egr1 mediating VEGF-induced tissue factor expression in the retinal capillary endothelium. Graefes Arch Clin Exp Ophthalmol 2002;240:1003-1010.

19 Coughlin CM, Salhany KE, Wysocka M, et al. Interleukin-12 and interleukin-18 synergistically induce murine tumor regression which involves inhibition of angiogenesis. J Clin Invest 1998;101:1441-1452.

20 Mallat Z, Silvestro JS, Le Ricousse-Roussanne S, et al. Interleukin-18/interleukin-18 binding protein signaling modulates ischemia-induced neovascularization in mice hindlimb. Circ Res 2002;91:441-448.

21 Hayakawa Y, Takeda K, Yagita H, et al. IFN-gammamediated inhibition of tumor angiogenesis by natural killer T-cell ligand, alpha-galactosylceramide. Blood 2002;100:1728-1733.

22 Zetter BR. Angiogenesis and tumor metastasis. Annu Rev Med 1998;49:407-424.

23 Sasamura H, Takahashi A, Miyao N, et al. Inhibitory effect on expression of angiogenic factors by antiangiogenic agents in renal cell carcinoma. Br J Cancer 2002;86:768-773.

24 Charteris DG, Lightman SL. Interferon-gamma (IFNgamma) production in vivo in experimental autoimmune uveoretinitis. Immunology 1992;75:463-467.

25 Caspi RR, Chan CC, Grubbs BG, et al. Endogenous systemic IFN-gamma has a protective role against ocular autoimmunity in mice. J Immunol 1994;152: 890-899.

26 Ishida S, Yamashiro K, Usui $\mathrm{T}$, et al. Leukocytes mediate retinal vascular remodeling during development and vaso-obliteration in disease. Nat Med 2003;9:781-788.

27 Olson JK, Girvin AM, Miller SD. Direct activation of innate and antigen-presenting functions of microglia following infection with Theiler's virus. J Virol 2001;75:9780-9789.

28 Prinz M, Hanisch UK. Murine microglial cells produce and respond to interleukin-18. J Neurochem 1999;72: 2215-2218. 